\title{
Muscle power predicts freestyle swimming performance
}

\author{
John A. Hawley MA, BSc(Hons), Maynard M. Williams MSc, Michael M. Vickovic MSc and \\ Phillip J. Handcock MSc \\ School of Physiotherapy, Faculty of Health Studies, Auckland Institute of Technology, Auckland, New Zealand
}

\begin{abstract}
The purpose of this study was to determine the relationship between non-invasive laboratory measures of 'muscle power' and swim performance over sprint $(50 \mathrm{~m})$ and middle-distance $(400 \mathrm{~m})$ events. Twenty-two swimmers performed an upper and lower body Wingate Anaerobic Test (WAT) and a maximal sustained power output test (MPO) for the upper body. Peak power (PP) and mean power (MP) were determined for the WAT, while peak sustained workload $\left(W L_{\text {peak }}\right)$ was determined for the MPO. Timed swims over $50 \mathrm{~m}$ and $400 \mathrm{~m}$ were undertaken by all swimmers during which the number of arm strokes per length was recorded. Highly significant relationships were found between sprint-swim speed (S50) and mean power of the arms $\left(M P_{\text {arms }}\right)(r=0.63, P<0.01)$, between $\mathrm{S} 50$ and mean power of the legs $\left(M P_{\text {legs }}\right)(r=0.76, P<$ 0.001 ) and between $S 50$ and the distance covered with each arm stroke (DS) $(r=0.91, P<0.001)$. Multiple regression analyses revealed that WAT power indices for the legs did not significantly increase explained variance in $\mathbf{S 5 0}$ above that of the arms. The relationship between $W L_{\text {peak }}$ and S400 was highly significant $(r=0.70, P<0.001)$ and indicates the importance of arm power in the longer distance swim events.
\end{abstract}

Keywords: Anaerobic power, muscle power, performance prediction, swimming, Wingate Test

Recently a number of studies have emphasized the important role of 'muscular power' as a determinant of athletic performance ${ }^{1-5}$. Correlations ranging from 0.71 to 0.90 have been reported between measures of short-term $(<45 \mathrm{~s})$ maximal upper body power and freestyle swimming speed ${ }^{6-9}$. With regard to running and cycling, it has been suggested that the primary variable that predicts endurance performance is the peak workload (or speed) an athlete can achieve during an incremental maximal test ${ }^{2-5}$.

The Wingate Anaerobic Test (WAT) has been utilized by a number of laboratories for the evaluation of short-term, high-intensity exercise, 10-12. The validity and reliability of the WAT has been documented previously ${ }^{13}$. With respect to the rela-

Address for correspondence: John A. Hawley, Liberty Life Chair of Exercise and Sports Science and MRC/UCT Bioenergetics of Exercise Research Unit, Department of Physiology, University of Cape Town Medical School, Observatory 7925, South Africa

(C) 1992 Butterworth-Heinemann Ltd 0306-3674/92/030151-05 tionship between this laboratory test and swimming performance, Inbar and Bar-Or ${ }^{7}$ found a correlation of -0.92 between mean power of the arms $\left(M P_{\text {arms }}\right)$ and 25-m freestyle time in a small group $(n=9)$ of young swimmers. Recently, Hawley and Williams ${ }^{1}$ reported highly significant relationships between $M P_{\text {arms }}$ and swim speeds over $50 \mathrm{~m}(r=0.83, P<$ $0.001)$ and $400 \mathrm{~m}(r=0.63, P<0.01)$ for male and female swimmers. To date only one study has assessed the relationship between the WAT for the lower body and swimming performance ${ }^{7}$.

We were interested in examining the role of muscle power and its relationship to swimming performance. Specifically, the aims of the current study were:

1. to assess the relationship between upper and lower body anaerobic power, as assessed by the WAT, and a $50-\mathrm{m}$ sprint-swim performance;

2. to determine whether a combination of arm and leg power improves prediction of sprint-swim performance above that of arm or leg power alone;

3. to assess the relationship between the peak sustained workload ( $\left.W L_{\text {peak }}\right)$ attained during a maximal sustained power output test (MPO) and swim performance over $400 \mathrm{~m}$.

\section{Materials and methods}

\section{Subjects and training}

Twelve male and ten female swimmers participated in this investigation after giving informed consent in accordance with the guidelines outlined by the American College of Sports Medicine ${ }^{14}$. Swimmers were familiar with both physiological and anthropometric testing procedures, having served as subjects in several previous studies ${ }^{1,15,16}$. Subjects had been training daily for the 3 months before this study, swimming on average $5000 \mathrm{~m} \mathrm{day}^{-1}, 6$ days a week. None of the subjects had participated in any formal strength-training programme for 6 months before investigation.

\section{Physiological testing}

Testing was undertaken over a 7-day period during the swimmers' competitive season. A mechanically braked Monark 818E cycle ergometer (Monark, Stockholm, Sweden), interfaced with an Apple IIE 
microcomputer, (Apple, Chicago, Illinois, USA) was employed for the lower body WAT. The warm-up protocol and determination of power outputs from the WAT have been described previously ${ }^{12,13}$. The forces chosen for the lower body WAT were $0.070 \mathrm{~kg} \mathrm{~kg}^{-1}$ body mass for males and $0.067 \mathrm{~kg} \mathrm{~kg}^{-1}$ body mass for females ${ }^{17}$. For upper body testing a Monark 881E ergometer (Monark, Stockholm, Sweden) was interfaced with a microcomputer. Calculation of WAT indices for the upper body test and the warm-up protocol employed have been described elsewhere ${ }^{1}$. Forces for the upper body WAT were $0.037 \mathrm{~kg} \mathrm{~kg}^{-1}$ body mass and $0.029 \mathrm{~kg} \mathrm{~kg}^{-1}$ body mass for males and females respectively ${ }^{10}$. The WAT data were not corrected for inertia of the flywheel ${ }^{18}$. However, power measurements were not initiated until swimmers had attained unresisted acceleration of the ergometer flywheel in accordance with the methodology of a previous study ${ }^{10}$.

The MPO consisted of arm cranking at 80 r.p.m. against a progressively increasing workload until volitional fatigue. The initial work rate was $24 \mathrm{~W} \mathrm{~min}^{-1}$ for males and $16 \mathrm{~W} \mathrm{~min} \mathrm{~m}^{-1}$ for females. The power output was increased every 2 min by $16 \mathrm{~W}$ until subjects could no longer maintain a cadence of 70 r.p.m. For each test $W L_{\text {peak }}$ was defined as the highest workload the subject completed. If a workload was not completed, $W L_{\text {peak }}$ was determined from the following formula:

$$
W L_{\text {peak }}(W)=W L_{\text {com }}+(t / 120 \times \Delta W L)
$$

where $W L_{\text {com }}$ was the last workload which the subject completed for $120 \mathrm{~s}, t$ was the time(s) the final uncompleted workload was sustained and $\Delta W L$ was the final workload increment.

Subjects rested for $24 \mathrm{~h}$ before testing. During both the upper body tasks, subjects were instructed to remain seated, and during all laboratory tests they were given strong verbal encouragement.

\section{Anthropometric data}

Skinfold measurements were taken at the biceps, triceps, suprailiac, subscapular, mid-axilla, pectoral, abdominal, thigh and calf folds ${ }^{19}$. Lean body mass (LBM) and percentage body fat (\% fat) were estimated from skinfold measurements ${ }^{20}$. Arm length (AL) and leg length (LL) were also measured. AL was taken as the distance from acromion to stylion and LL was taken as the distance from trochanterion to sphyrion $^{19}$.

\section{Swimming performance}

Timed swims were performed within $72 \mathrm{~h}$ of laboratory testing in a 25-m (short-course) pool. Subjects arrived at the pool and undertook a warm-up supervised by their coach. The $50-\mathrm{m}$ time-trial was conducted first with a recovery period of $60 \mathrm{~min}$ before the $400-\mathrm{m}$ swim. Subjects began the swim in the water with timing being started manually when their feet left the wall of the pool. Subjects were instructed to produce maximal effort. Three independent assessors recorded the swim times with the average of these being taken as representative of each subject's performance. Times were subsequently converted to speeds $(S)$ for the two swim distances. The number of strokes taken per length was also recorded in order to calculate the distance covered with each stroke (DS, m stroke $\left.{ }^{-1}\right)$. Although this method overestimates DS by $4-5 \%$ due to the push off from the side of the pool ${ }^{21}$, this is a systematic overestimation which does not greatly influence subsequent comparisons between swimmers ${ }^{22}$. Therefore, in accordance with previous studies ${ }^{22,23}$ no attempt was made to derive a correction factor for DS. A stroke index (SI) was determined as previously described by Costill et al. ${ }^{24}$.

\section{Statistical analysis}

Pearson product moment correlations and multiple linear regression analyses were performed using the computer software package SYSTAT (Systat, Evanstown, Illinois). Results were considered significant where $P<0.05$.

\section{Results}

The physical characteristics of the subjects are displayed in Table 1. With the exception of LBM there were no significant differences between male and female swimmers for the characteristics measured.

Table 2 shows the performance data for the $50-\mathrm{m}$ and $400-\mathrm{m}$ timed swims. Sprint-swim performances for $50 \mathrm{~m}$ ranged from $1.39 \mathrm{~m} \mathrm{~s}^{-1}$ to $1.85 \mathrm{~m} \mathrm{~s}^{-1}$ for males and from $1.42 \mathrm{~m} \mathrm{~s}^{-1}$ to $1.79 \mathrm{~m} \mathrm{~s}^{-1}$ for females, indicating a wide variation in sprint-swim ability. Both S50 and DS50 were significantly greater $(P<$ 0.05) for males than females. There were, however, no significant differences with respect to $\mathrm{S} 400$ and DS400.

Table 3 displays the power output values for the upper and lower body WAT and MPO. Significant

Table 1. Descriptive characteristics of swimmers

\begin{tabular}{lcccc}
\hline Subjects & $\begin{array}{c}\text { Age } \\
(\text { years })\end{array}$ & $\begin{array}{c}\text { Body mass } \\
(\mathrm{kg})\end{array}$ & $\begin{array}{c}\text { LBM } \\
(\mathrm{kg})\end{array}$ & $\begin{array}{c}\text { Body fat } \\
(\%)\end{array}$ \\
\hline Males $(n=12)$ & $13.6(1.2)$ & $54.4(7.6)$ & $44.3(8.2)$ & $18.6(4.9)$ \\
Females $(n=10)$ & $13.2(1.9)$ & $56.2(10.1)$ & $41.9(6.6)$ & $25.4^{*}(4.1)$
\end{tabular}

Values are mean(s.d.); LBM, lean body mass

* Significantly greater than for males, $P<0.05$

Table 2. Performance characteristics of the sprint and middledistance swims

\begin{tabular}{lllll}
\hline Subjects & \multicolumn{1}{c}{$\begin{array}{c}S 50 \\
\left(\mathrm{~m} \mathrm{~s}^{-1}\right)\end{array}$} & $\begin{array}{c}\text { DS50 } \\
(m \text { stroke }\end{array}$ & $\begin{array}{c}S 400 \\
\left(\mathrm{~m} \mathrm{~s}^{-1}\right)\end{array}$ & $\begin{array}{c}D S 400 \\
(m \text { stroke }\end{array}$ \\
\hline Males & $1.69^{*}(0.15)$ & $1.26^{*}(0.13)$ & $1.34(0.12)$ & $1.12(0.23)$ \\
Females & $1.55(0.12)$ & $1.11(0.13)$ & $1.27(0.09)$ & $1.08(0.07)$
\end{tabular}

Values are mean (s.d.); S50, swim speed over $50 \mathrm{~m}$; DS50,

distance covered with each stroke during the 50-m swim; $\$ 400$, swim speed over $400 \mathrm{~m}$; DS400, distance covered with each stroke during the 400-m swim.

*Significantly greater than for females, $P<0.05$ 
Muscle power and swimming performance: J. A. Hawley et al.

Table 3. Power outputs for the Wingate Anaerobic Test and the maximum sustained power output test

\begin{tabular}{|c|c|c|c|c|c|}
\hline & \multicolumn{3}{|c|}{ Upper body } & \multicolumn{2}{|c|}{ Lower body } \\
\hline & $P P$ & $M P$ & $W L_{\text {peak }}$ & $P P$ & $M P$ \\
\hline $\begin{array}{l}\text { Males } \\
\text { Females }\end{array}$ & $\begin{array}{l}4.89^{*}(0.59) \\
3.65(0.47)\end{array}$ & $\begin{array}{l}3.74^{*}(0.36) \\
2.82(0.29)\end{array}$ & $\begin{array}{l}1.75(0.46) \\
1.39(0.39)\end{array}$ & $\begin{array}{c}10.75+(0.94) \\
9.51(0.96)\end{array}$ & $\begin{array}{l}8.26(0.97) \\
6.58(0.78)\end{array}$ \\
\hline
\end{tabular}

All values, expressed in $W \mathrm{~kg}^{-1}$, are mean(s.d.) $P P$, peak power; $M P$, mean power; $W L_{\text {peak, }}$ peak sustained workload

*Significantly greater than for females, $P<0.001$

tSignificantly greater than for females, $P<0.01$

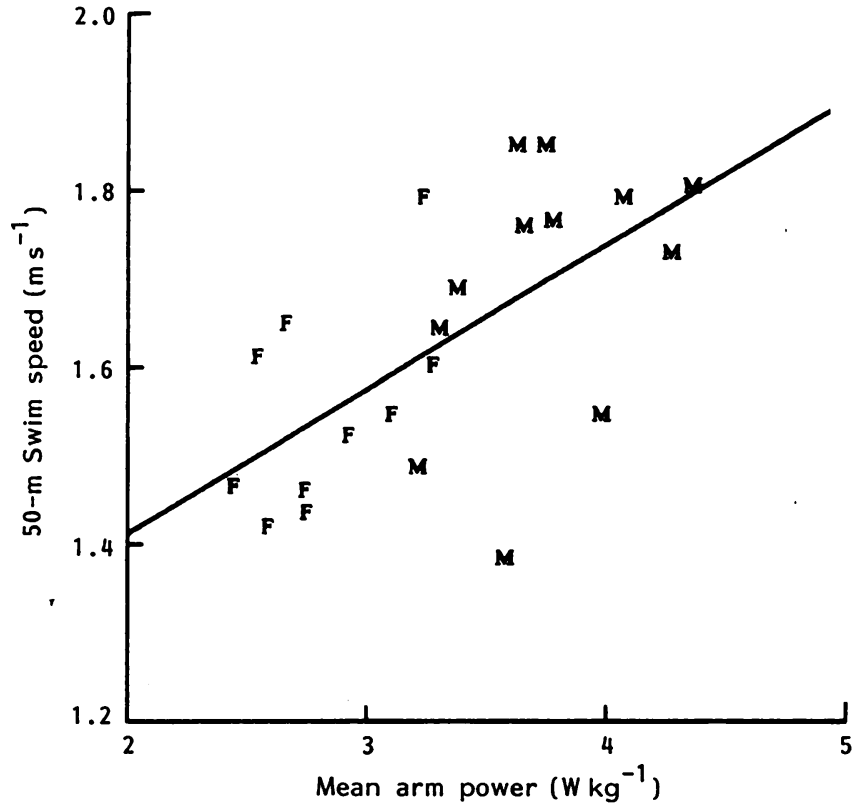

Figure 1. Relationship between sprint-swim speed (S50) and mean power of the arms ( $\left.M P_{\text {arms }}\right)$ for male $(M)$ and female (F) swimmers. $r=0.63 ; y=0.163 x+1.087$; s.e.e. $=$ $0.121 ; n=22$

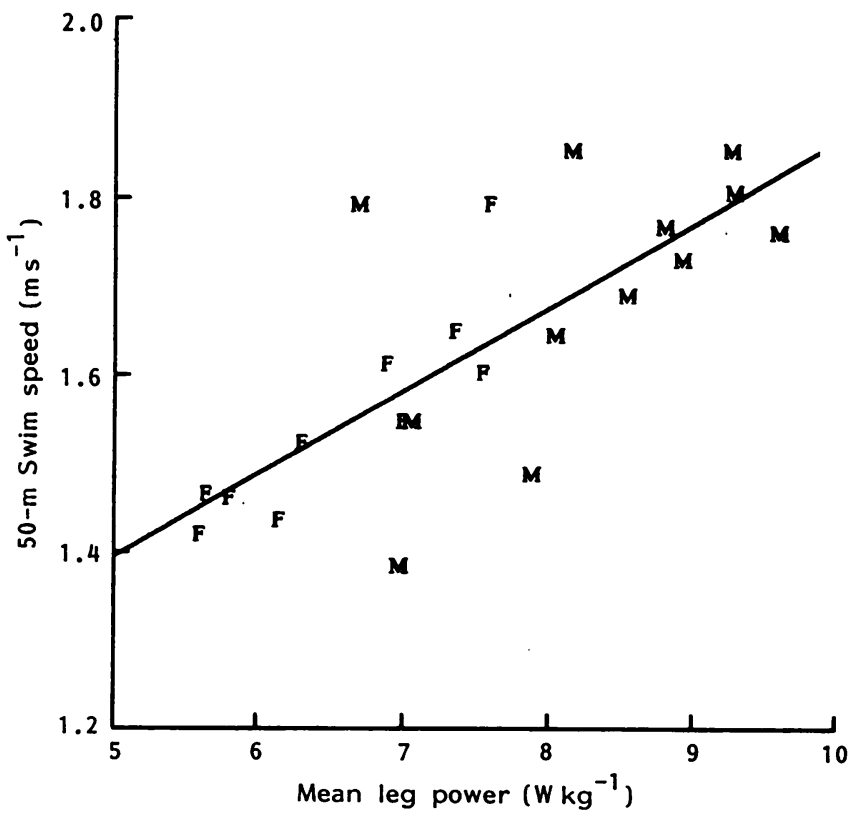

Figure 2. Relationship between sprint-swim speed (S50) and mean power of the legs $\left(M P_{\text {legs }}\right)$ for male $(M)$ and female (F) swimmers. $r=0.76 ; y=0.93 x+0.928$; s.e.e. $=$ $0.100 ; n=22$ differences in power output were found between male and female swimmers for peak power of the arms $\left(P P_{\text {armsi }} P<0.001\right)$, mean power of the arms $\left(M P_{\text {arms }} ; P<0.001\right)$, peak power of the legs $\left(P P_{\text {legs }} ; P\right.$ $<0.01)$ and mean power of the legs $\left(M P_{\text {legsi }} P<\right.$ 0.001 ). There were no significant differences between male and female subjects with respect to $W L_{\text {peak. }}$

Figure 1 shows the relationship for $\mathrm{S} 50$ and $M P_{\text {arms }}$ along with the associated regression equation, while Figure 2 displays the relationship betwen S50 and $M P_{\text {legs. }}$. Multiple regression analysis revealed that WAT indices for the arms or the legs did not significantly increase the explained variance in S50 above that of each separately. Further, gender did not add significantly above WAT power indices in the prediction of sprint-swim speed and therefore single regression lines combining both males and females are displayed.

Step-wise multiple regression analysis revealed the best predictors of S50 were $M P_{\text {legs }} \mathrm{DS} 50$ and $\mathrm{AL}(r=$ $0.956, P<0.001$; s.e.e. $=0.48$ ).

Figure 3 displays the relationship between $\mathrm{S} 400$ and $W L_{\text {peak }}$ for male and female subjects, along with the associated regression equation.

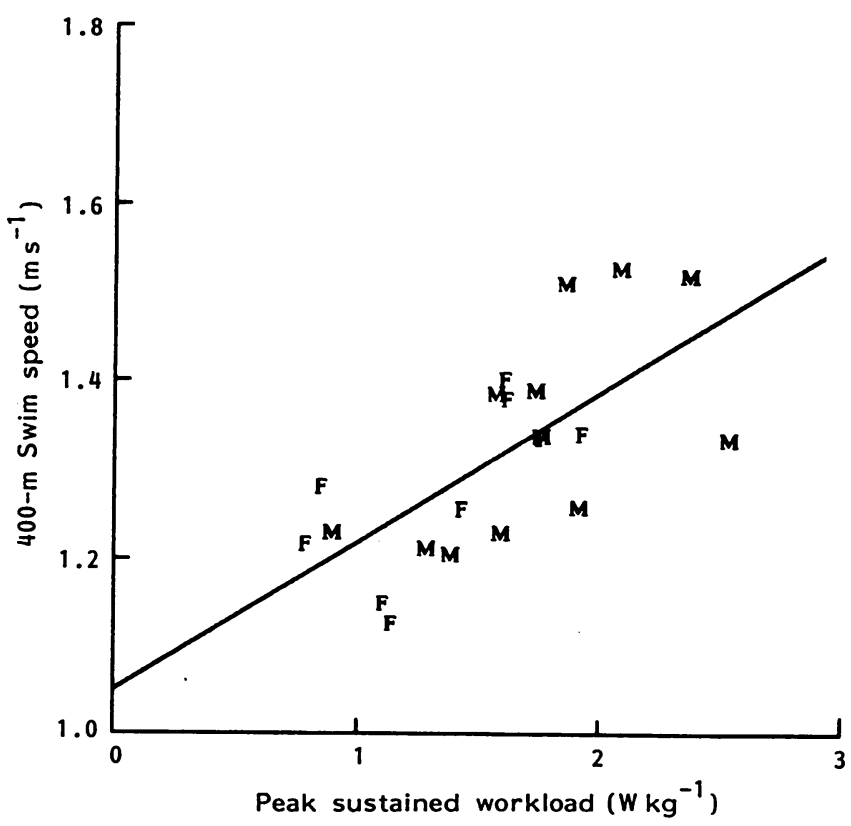

Figure 3. Relationship between middle-distance swim speed (S400) and maximal sustained workload ( $\left.W L_{\text {peak }}\right)$ for male $(M)$ and female (F) swimmers. $r=0.70 ; y=0.167 x+$ 1.051 ; s.e.e. $=0.086 ; n=22$ 


\section{Discussion}

This study shows that strong relationships exist between upper and lower body power output and both sprint $(50 \mathrm{~m})$ and middle-distance $(400 \mathrm{~m})$ freestyle-swim performance.

In the absence of longitudinal stature data, ancillary evidence of secondary sex characteristics and age of menarche, we cannot explain any variance in physiological and performance parameters which may be due to differences in the level of maturation of our swimmers ${ }^{19}$. Therefore, we have considered the data from the standpoint of the chronological age of our subjects only.

Our correlation of 0.63 between $M P_{\text {arms }}$ and $S 50$ is somewhat lower than previously reported ${ }^{1,7,15}$. Further, Inbar and Bar-Or ${ }^{12}$ found that for untrained children, anaerobic performance with the arms was $60-70 \%$ of that achieved by the legs; in the current study the corresponding figure was only $45 \%$. Thus, there appears to have been a reduction in the ratio of arm to leg power in our subjects. This may, in part, explain why the relationships between the WAT power indices for the lower body and S50 were higher than those found for the upper body. The possibility also exists that the 'normal' arm:leg power ratio in untrained children ${ }^{12}$ is different in swimmers.

Alternatively, the different ratio of arm:leg power found in the present study may be related to the long-distance swim-training our subjects were undertaking, which has a primary reliance on the arms $\mathrm{s}^{25}$ rather than the legs. As noted by Costill et al. ${ }^{26}$, it is not uncommon for swimmers to experience a marked reduction in muscle power during periods of intense training, which can subsequently be reversed by a reduction in training volume.

Our correlation of 0.76 between $M P_{\text {legs }}$ and $S 50$ is also lower than the figure of 0.90 reported by Inbar and $\mathrm{Bar}-\mathrm{Or}^{7}$. The discrepancy between the two correlations can probably be attributed to the different criterion swim distances to which power output was related. The study of Inbar and $\mathrm{Bar}^{-\mathrm{Or}^{7}}$ employed a 25-m sprint-swim, whereas a distance of $50 \mathrm{~m}$ was chosen for the current investigation. However, as noted previously ${ }^{1}$, large subject numbers would be required to provide the statistical power necessary to detect small differences between correlation coefficients.

The highly significant relationship $(r=0.70, P<$ 0.001 ) found between $W L_{\text {peak }}$ and $S 400$ in the present study is notable. It has been suggested ${ }^{2-5}$ that the variable that best predicts endurance performance is the highest workload an athlete attains during a maximal test. Noakes et al. ${ }^{4}$ and Scrimgeour et al. ${ }^{5}$ found that for running, the peak treadmill speed achieved in a maximal test was a better predictor of performance than $\dot{V}_{\mathrm{O}_{2 \max }}$. Recently, Hawley and Noakes $^{2}$ reported a highly significant relationship $(r=0.91, P<0.001)$ between the peak power a cyclist attained during an exhaustive laboratory cycling test and a $20-\mathrm{km}$ cycle time-trial. Further, Costill et al. ${ }^{24}$ report only a moderate relationship $(r=0.43)$ between a swimmer's time in an all-out 400 yard $(365.8 \mathrm{~m})$ swim, and $\dot{V} \mathrm{O}_{2 \max }$. We have previously observed that the correlation between $\dot{V}_{\mathrm{O}_{2} \text { max }}$ deter- mined during the MPO laboratory test and S400 is in the order $r=0.42-0.48$ (Hawley et al., unpublished observations), which is almost identical to the relationship found by Costill et al. ${ }^{24}$ for $\dot{V}_{\mathrm{O}_{2 \max }}$ measured after a 400 yard maximal swim.

In our own preliminary studies we have noted that the fastest swimmers not only display high anaerobic power outputs but also high peak sustained power outputs, as determined by the $W L_{\text {peak }}$ they achieve during a progressive, incremental maximal arm power test (Hawley and Williams, unpublished observations). In the present investigation the relationship between $M P$ arms and $W L_{\text {peak }}$ was $0.55(P<$ 0.01 ). Jones and McCartney ${ }^{27}$ have previously reported a high relationship between $\dot{V}_{2 \max }$ and total work output during $30 \mathrm{~s}$ of maximal isokinetic exercise. These workers suggested that 'changes in muscle function' could contribute to increases in maximal short-term work capacity evidenced after a period of training.

With respect to sprint-swimming speed and stroke mechanics, males were faster $(P<0.05)$ and covered a greater distance $(P<0.05)$ with each stroke than females. Correlations between DS50 and S50 were 0.93 for males and 0.82 for females. Other studies ${ }^{22-24}$ have indicated the importance of DS in determining a swimmer's speed.

The single best predictor of sprint-swim performance in the present study was the swimmer's stroke index (SI50; $r=0.97$ for males, $r=0.94$ for females). The SI $(S \times D S)$ assumes that for a given speed the swimmer who has the greatest DS has the most efficient swimming technique ${ }^{24}$. The SI is obviously sensitive to a swimmer's biomechanical and technical competence. Unfortunately, however, the SI cannot be considered an independent predictor of S50 since the derivation of this parameter incorporates S50.

With regard to middle-distance performance, there were no significant differences between males and females for S400 and DS400. Correlations between DS400 and S400 in the present study ( $r=0.42$ for males, $r=0.43$ for females) are lower than those reported by Costill et al. ${ }^{24}$. These workers found the single best predictor of swim performance over 400 yards $(365.8 \mathrm{~m})$ in male and female competitive swimmers was DS400 ( $r=0.88)$. The best predictor of middle-distance swim performance in the present investigation was the peak workload the subject attained during the MPO test $(r=0.70, P<0.001)$.

The relationship between $\mathrm{S} 50$ and $\mathrm{S} 400$ in the current study was strong ( $r=0.80$ for males, $r=0.38$ for females), and illustrates that speed is still a large component of the $400-\mathrm{m}$ event. Sharp et al. ${ }^{9}$ found an almost identical correlation $(r=0.82)$ between 25 yard $(22.86 \mathrm{~m})$ sprint velocity and 500 yards $(457.2 \mathrm{~m})$ time and suggested that 'arm power' was a necessary component for success in the longer distance event.

In summary, this study has demonstrated that significant relationships exist between laboratory measures of power and swim performance over both sprint and middle-distance events. Although our study cannot determine whether the relationship between our laboratory measures of power and swim performance are causal or merely coincidental, previous studies 9,29 reveal that for the upper body 
the relationship is likely to be causal $^{28}$. Further, previous investigations with swim-power tests have shown that small differences in muscle power are associated with measurable performance improvements in freestyle sprint-swimming ${ }^{29-31}$. Therefore, swimmers in events up to $400 \mathrm{~m}$ may benefit from training which aims to improve arm and leg power. In those swimmers who possess a high level of arm and leg power, factors such as stroke mechanics may contribute more to the differences in performance seen between these individuals.

As the majority of individual swim events have a major reliance on anaerobic metabolism ${ }^{32}$, the necessity for large volumes $\left(>10000 \mathrm{~m} \mathrm{day}^{-1}\right)$ of moderate intensity 'aerobic overload training' for these athletes must be seriously questioned. As recently noted by Costill et $a l^{33}$ it is difficult to understand how training at speeds that are markedly slower than competitive (race) pace for $3-4 \mathrm{~h} \mathrm{day}^{-1}$ will prepare the swimmer for the supramaximal efforts of competition'.

Taken collectively, the results of the current and other studies $1,7,26,31$ suggest that 'muscle power' is an important determinant of both sprint and middledistance swimming performance. Although the mechanisms underlying the relationship between 'muscle power' and swimming performance cannot be explained by the current study, future investigations should focus on the examination of different training regimens and their influence on muscle contractility ${ }^{3}$. Such training studies will help elucidate those factors responsible for performance difference between individuals.

\section{Acknowledgements}

This study was supported by a grant from Fitness Concepts (NZ) Limited.

\section{References}

1 Hawley JA, Williams MM. Relationship between upper body anaerobic power and freestyle swimming performance. Int $J$ Sports Med 1991; 12(1): 1-5.

2 Hawley JA, Noakes TD. Peak sustained power output predicts $\mathrm{VO}_{2 \max }$ and performance in trained cyclists. Eur $J$ Appl Physiol 1992; 64.

3 Noakes TD. Implications of exercise testing for prediction of athletic performance: a contemporary perspective. Med Sci Sports Exerc 1988; 20: 319-30.

4 Noakes TD, Myburgh KH, Schall R. Peak treadmill running velocity during the $\dot{V}_{\mathrm{O}_{2} \max }$ test predicts running performance. J Sports Sci 1990; 8: 35-45.

5 Scrimgeour AG, Noakes TD, Adams B, Myburgh K. The influence of weekly training distance on fractional utilization of maximum aerobic capacity in marathon and ultramarathon runners. Eur J Appl Physiol 1986; 55: 202-9.

6 Costill DL. Use of a swimming ergometer in physiological research. Res Quart 1966; 37: 564-7.

7 Inbar O, Bar-Or O. Relationship of anaerobic and aerobic arm and leg capacities to swimming performance of 8-12 year old children. In: Shephard R, Lavellee, R, eds. Quebec: Pelican, 1977: 283-92.

8 Miyashita $M$, Kanshisa $H$. Dynamic peak torque related to age, sex and performance. Res Quart 1979; 50: 249-55.
9 Sharp RL, Troup JP, Costill DL. Relationship between power and sprint freestyle swimming. Med Sci Sports Exerc 1982; 14: 53-6.

10 Blimkie CJR, Roache P, Hay JT, Bar-Or O. Anaerobic power of arms in teenage boys and girls: relationship to lean tissue. Eur J Appl Physiol 1988; 57: 677-83.

11 Hawley JA, Williams MM, Hamling GC, Walsh RM. Effects of a task-specific warm-up on anaerobic power. $\mathrm{Br} J$ Sports Med 1989; 23: 233-6.

12 Inbar O, Bar-Or O. Anaerobic characteristics in male children and adolescents. Med Sci Sports Exerc 1986; 18: 264-9.

13 Bar-Or $O$. The Wingate Anaerobic Test. An update on methodology, reliability and validity. Sports Med 1987; 4: 381-94.

14 American College of Sports Medicine. Policy statement regarding the use of human subjects and informed consent. Med Sci Sports Exerc 1989; 21(4): v.

15 Williams MM, Hawley JA. Relationship between upper body anaerobic power and freestyle swimming. Med Sci Sports Exerc 1989; 21: S104.

16 Hawley JA, Williams MM. Dietary intakes of age-group swimmers. Br J Sports Med 1991; 25: 154-8.

17 Dotan R, Bar-Or O. Load optimization for the Wingate Anaerobic Test. Eur J Appl Physiol 1983; 51: 409-17.

18 Lakomy HKA. Measurement of work and power output using friction-loaded cycle ergometers. Ergonomics 1986; 29: 509-17.

19 Ross WD, Marfell-Jones MJ. Kinanthropometry. In: MacDougall JD, Wenger HA, Green HJ, eds. Physiological Testing of the Elite Athlete. Fitness and Amateur Sport, Government of Canada: Canadian Association of Sport Sciences, 1982: 75-115.

20 Russo PF, Wade KJ. The estimation of the percentage of body fat in Australian children using anthropometric measures and body density from hydrostatic weighing. Trans Menzies Found 1983; 5: 59-81.

21 Thayer AL, Hay JG. Motivating start turn improvement. Swim Technique 1984; 20: 17-20.

22 Craig AB, Skehan PL, Pawelczyk JA, Boomer WL. Velocity, stroke rate, and distance per stroke during elite swimming competition. Med Sci Sports Exerc 1985; 17: 625-34.

23 Craig $A B$, Pendergast DR. Relationship of stroke rate, distance per stroke and velocity in competitive swimmers. Med Sci Sports Exerc 1979; 11: 278-83.

24 Costill DL, Kovaleski J, Porter D, Kirwan J, Fielding RA, King D. Energy expenditure during front crawl swimming: predicting success in middle-distance events. Int J Sports Med 1985; 6: 266-70.

25 Holander AP, de Groot G, van Ingen Schenau GJ, Kahman R, Toussaint HM. Contribution of the legs to propulsion in front crawl swimming. In: Ungerechts BE, Wilke K, Reischle K, eds. Swimming Science $V$. Champaign, Illinois: Human Kinetics, 1988: 39-43.

26 Costill DL, King DS, Thomas R, Hargreaves M. Effects of reduced training on muscular power in swimmers. Phys Sportsmed 1985; 13: 94-101.

27 Jones NL, McCartney N. Influence of muscle power on aerobic performance and the effects of training. Acta Med Scand 1986; 711: 115-22

28 Hay JG, Guimaraes ACS. A quantitative look at swimming biomechanics. Swim Technique 1983; 20: 11-17.

29 Strass D. Effects of maximal strength training on sprint performance of competitive swimmers. In: Ungerechts $B E$, Wilke K, Reischle K, eds. Swimming Science V. Champaign, Illinois: Human Kinetics, 1988: 149-56.

30 Costill DL, Sharp R, Troup J. Muscle strength: contribution to sprint swimming. Swim World 1980; 21: 29-34.

31 Costill DL, King DS, Holdren A. Sprint swim speed vs swimming power. Swim Technique 1983; 20: 20-21.

32 Sawka MN, Knowlton RG, Miles DS, Critz JB. Postcompetition blood lactate concentrations in collegiate swimmers. Eur J Appl Physiol 1979; 41: 93-9.

33 Costill DL, Thomas R, Robergs RA et al. Adaptations to swimming training: influence of training volume. Med Sci Sports Exerc 1991; 23: 371-7. 